\title{
Serpentes Copulantes
}

Um Édipo, de Armando Nascimento Rosa A história que não foi contada: um mitodrama fantasmático em um ato.

\author{
Marvin Carlson
}

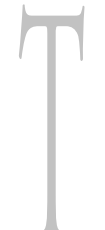

anto o título quanto o subtítulo da releitura que Armando Nascimento Rosa faz de Édipo fornecem pistas valiosas sobre o modo como ela deve ser abordada, seja por um leitor ou por um produtor. A história de Édipo, apesar de ou talvez por causa da posição central que Aristóteles conferiu à versão de Sófocles, não inspirou nem de perto o mesmo número de releituras subsequentes da história de Antígona, sua filha infeliz, ou, nesse sentido, de Orestes ou Electra, os filhos da outra famosa casa amaldiçoada, a casa dos Atreus. É muito menos provável encontrar espectadores que conheçam tratamentos dramáticos alternativos da história de Édipo, mesmo entre um público de teatro razoavelmente bem-informado, que encontrar espectadores que conheçam releituras destes outros mitos ou de quase-mitos mais recentes, que inspiram tratamentos dramáticos múltiplos, como Joana D'Arc, Don Juan e Fausto. No entanto, o título dado por Rosa chama imediatamente a nossa atenção para a multiplicidade (e, por conseguinte, para a falta de fixidez) dessa famosa história, ao chamá-la Um Édipo, assim como fez Paul Valéry com o título Meu Fausto, ou Jean Giraudoux, outro releitor do mito, muito autoconsciente, que deu o famoso título Amphytrion 38 para um de seus trabalhos mais conhecidos, chamando a atenção de maneira singular e autoconsciente para as numerosas versōes anteriores.

Um Édipo, como apontei, traz a multiplicidade para o primeiro plano, como o conceito de suplemento em Derrida. Ele não apenas chama a atenção para o fato das múltiplas versōes, mas também renuncia à reivindicação, implícita em muitas versões anteriores, de ser a forma única e definitiva de recontar a história, pelo menos para o seu tempo e para o seu público. Não se pode dizer que a versão de Rosa seja arbitrária, mas ela com certeza tem um elemento de singularidade, na medida em que aborda até as partes mais conhecidas da lenda por caminhos inesperados, apresenta elementos conhecidos na antiguidade, mas quase esquecidos hoje em dia, e ainda acrescenta outro material que é exclusivo da sua forma de recontar. Tamanha é a engenhosidade do entrelaçamento, que somente de um muito bem-informado estudioso dos clássicos seria possível esperar a capacidade de distinguir o mito antigo do novo.

Isso nos leva ao subtítulo descritivo, $\mathrm{Mi}$ todrama fantasmático em um ato. O papel dos fantasmas, de um modo geral, não é nem de perto tão importante no palco da tragédia grega quanto será num momento posterior da his-

Marvin Carlson é Professor da City University of New York. Tradução de Celina Lage. Versão original disponível em <http://fogogrego.wunderblogs.com/archives/012009.html>. 
tória do teatro (o fantasma de Clytemnestra é uma notável exceção). Entretanto, a noção de assombração, no sentido que era tão determinante na obra de Ibsen e de O'Neill, isto é, a influência inevitável das açôes do passado, das decisóes do passado, dos erros do passado, dos crimes do passado, é absolutamente fundamental para essas obras. Em nenhum lugar essa questão pode ser percebida_com maior clareza que na importância da maldição da família, sobretudo nos seus dois grandes exemplos, a casa de Lábdaco e a casa de Atreu (essencialmente como aponta a peça de Rosa para o leitor ou espectador atento - em conexão com os antecedentes nebulosos onde a maldição começa). Profundamente entrelaçada com a maldição da família, está a profecia, o que é demonstrado com clareza nas histórias de Laio e Édipo. Essa atenção à resolução da profecia e da maldição confere à maior parte das tragédias gregas um efeito retrospectivo, e, mais uma vez, em nenhum outro lugar esse aspecto é tão claro quanto no Édipo Rei de Sófocles, muitas vezes tido como o exemplo primordial do método retrospectivo no teatro clássico, que encontrou em Ibsen o seu mestre moderno. (Há muito tempo, corre o dito popular entre os estudiosos de Ibsen que qualquer uma de suas peças poderia ser intitulada Fantasmas). Em peças como essas, a ação principal se dá num acúmulo de revelaçôes sobre o passado, até o ponto em que os segredos escondidos são revelados - a despeito das consequências catastróficas que venham em seguida - e a peça pode terminar.

O "mitodrama fantasmático" de Rosa se fundamenta nessa orientação retrospectiva do olhar, característica de muitas tragédias gregas, ao deslocar a ação para uma etapa mais à frente no futuro. Em vez de encontrarmos os protagonistas, que ainda estão vivos, revelando gradualmente os segredos uns dos outros até o momento da morte, vamos além desse ponto, e encontramos no elenco uma mistura de personagens que ainda estão vivos, personagens mortos que ainda estão conscientes e personagens videntes suspensos entre a vida e a morte - todos eles ainda envolvidos no jogo macabro de cavar cada vez mais fundo nos sombrios e terríveis segredos reprimidos do passado. O efeito lembra menos as peças de Ibsen que as peças de câmara de Strindberg, nas quais os vivos, os visionários e os mortos interagem numa dança macabra de recriminação e recordação. Num momento posterior da peça, Manto faz uma observação que bem poderia ser de um personagem da Sonata Fantasma: "Como é estranho este mundo. Os vivos e os mortos coabitam lado a lado uns com os outros, e torna-se difícil distingui-los.”

Como mais um de seus ilustres predecessores, Eurípides, Rosa lança mão de variantes alternativas e menos familiares do conhecido mito para colocar a história numa direção totalmente nova e levantar novas questôes. O espectador, ao chegar ao teatro e consultar o programa, vai achar a maioria dos nomes familiar o suficiente - Édipo, Jocasta, Tirésias e Laio. Talvez ele também reconheça o nome de Pélops, mas por associação com a outra grande casa amaldiçoada, a do filho de Pélops, Atreu. Apenas os estudiosos dos clássicos, entretanto, devem reconhecer os outros dois nomes, Crísipo e Manto, embora eles de fato tenham papeis importantes na complexa rede mítica que enlaça tanto Laio quanto Édipo. Manto, na verdade, aparece como personagem importante numa peça remanescente, o Édipo de Sêneca, nitidamente conhecida por Rosa, mas não por muitos outros, nem mesmo por estudantes de teatro, uma vez que foi tão totalmente obscurecida pela reputação da versão de Sófocles.

Sêneca, no entanto, oferece uma série de elementos muito úteis para Rosa, especialmente na parte central da peça, que revela tanto o passado negro quanto o futuro obscuro de Édipo e de sua família. Em outras peças, a terrível visão é atribuída ao oráculo de Delfos ou ao coro, mas, na peça de Sêneca, ela fica a cargo de Manto, filha e assistente de Tirésias. Nesta versão, Tirésias perdeu o dom da profecia por causa da sua idade avançada, mas, por sorte, tinha treinado sua filha Manto na arte - análoga, embora menos importante - da adivinhação. Assim, um 
touro e uma novilha são sacrificados, e Manto, como sacerdotisa délfica, lê os presságios de Apolo nas visões induzidas pelo incenso e nas configurações das entranhas dos animais sacrificados. Através de imagens medonhas e sangrentas, ela evoca o assassinato de Laio, o incesto de Édipo, sua cegueira, o suicídio de Jocasta e até mesmo o conflito e o fratricídio de seus filhos, embora estas imagens, apesar de claras o suficiente para o público, permaneçam obscuras para Édipo. Ele quer saber especificamente o nome do assassino de Laio, uma pergunta direta que, segundo Tirésias, só pode ser respondida pelo próprio fantasma do rei assassinado.

No lugar da leitura das entranhas, realizada por Manto, essa evocação do espírito é feita por Tirésias num misterioso foco fora de cena, através de rituais secretos. Creonte é testemunha e retorna para informar Édipo que o fantasma foi evocado com sucesso, que ele estava coberto de sangue e acusou Édipo como assassino de Laio e violador do leito de Jocasta. Como em Sófocles, Édipo se recusa a aceitar essa revelação e acusa Creonte e Tirésias de estarem conspirando para tirá-lo do trono. A versão de Sêneca, menos familiar, tem ecos claros na peça de Rosa - a presença e a importância de Manto como aprendiz e assistente de Tirésias, a importância central dos fantasmas como testemunhas e, particularmente, a presença de Laio, que serve aqui, como em Sêneca, como o fantasma que nomeia Édipo como o assassino. Na versão de Rosa, entretanto, há uma série de mudanças significativas. Em primeiro lugar, Laio não é evocado por Tirésias, como testemunha forçada, mas toma a iniciativa e de fato toma posse do corpo do vidente para revelar segredos do passado que o próprio fantasma quer dar a conhecer. Em segundo lugar, e o que é mais importante, a nomeação de Édipo como o assassino de Laio não é a revelação final nem a revelação mais importante a ser feita. Isso vai ficar a cargo do fantasma de Crísipo - essa é a mudança mais importante que Rosa faz na história tradicional e a chave para a reorientação que ele dá às suas imagens e questôes.
Crísipo, ao contrário de Manto, não aparece em nenhuma das peças gregas remanescentes, embora tenha sido assunto de uma peça perdida de Eurípedes e de uma peça de Ácio. Atreu e Tiestes, que são muito mais familiares aos estudantes da Tragédia Grega, eram os filhos do Rei Pélops e de sua esposa Hipodâmia. Diz-se que Crísipo era um filho mais velho, de um casamento anterior de Pélops com uma ninfa. Por causa de sua grande beleza, Crísipo acabou por se tornar objeto de amor do Rei Laio (tal beleza, com suas consequências homossexuais, parece ser de família, já que o próprio Rei Pélops, quando jovem, atraiu a atenção de ninguém menos que o Rei Poseidon). A tradição dramática da história de Édipo estava focada nos involuntários, porém repreensíveis, pecados de Édipo, ou seja, parricídio e incesto. O pecado anterior de Laio, bastante voluntário, a violação homossexual do filho de seu anfitrião, foi omitido desta narrativa. Ao reintroduzir Crísipo, e numa posição central, Rosa não apenas amplia a história de Édipo, mas dá a ela um foco completamente novo, não só quanto à questão dos personagens, mas, o que é mais importante, no que diz respeito ao tema. Tradicionalmente, o centro emocional da lenda e a presumida primeira causa do sofrimento de Tebas tem sido a transgressão do incesto, que já estava bem clara na tradição sofocleana, mas que tinha recebido ainda mais destaque no século XX pelos escritos de Freud, que tornou o "complexo de Édipo" tão familiar na imaginação cultural do século XX como a "teoria da relatividade". $\mathrm{Na}$ versão de Rosa, a transgressão anterior de Laio, não de Édipo, se torna o segredo oculto, o pecado inicial, deslocando assim a atenção de um amor culturalmente proibido, o incesto, para outro, o homossexualismo, cujo imaginário permeia esta versão e dá a dinâmica que guia tanto a trama quanto as revelaçóes.

Rosa começa a peça no que parece ser um terreno familiar, com um solilóquio de Édipo, cego, que se passa nitidamente em algum ponto entre o Édipo Rei e o Édipo em Colono de Sófocles. Édipo ainda sofre a angústia da pri- 
meira peça, mas ainda não está se aproximando da transfiguração e da libertação da segunda. Sua cegueira não trouxe a esperada visão interior. A ira e a raiva, o ciclo de vingança e morte que ele quis interromper com o próprio sofrimento continua na geração seguinte. $\mathrm{O}$ espírito da Esfinge continua vivo. O segredo que Édipo fez vir à luz não proporcionou a libertação pretendida e ele agora se dá conta de que por trás deste segredo deve haver outro segredo ainda mais profundo, que ainda impulsiona as forças negras à sua volta. Quanto ao próprio comprometimento de Édipo, retornamos ao início da peça de Sófocles. Nela, Édipo, a pedido do Sacerdote de Zeus, revela que, aflito com o sofrimento de Tebas, enviou Creonte para o oráculo de Delfos para descobrir a fonte dessa dor, com a esperança de saber "a origem do mal que ataca Tebas.” Agora, concluídos todos os eventos da peça, o sofrimento continua e Édipo precisa perguntar de novo, iniciando, na peça de Rosa, uma nova busca dramática e uma nova ação dramática: "Pudesse eu saber a origem do mal que ataca Tebas." A origem que o Édipo de Sófocles pensou ter descoberto sobre o próprio passado é agora vista como inadequada e a outra origem que precisa ser descoberta está escondida ainda mais profundamente e num passado mais distante. Esta vai ser a questão deste drama.

Depois da cena de abertura de Édipo, acontece uma cena entre uma mulher mais jovem e outra mais velha - e aqui a peça revela seu significativo desvio da história tradicional e da forma tradicional de contá-la. A princípio, a identidade destas mulheres não está clara, embora a mais jovem fale sobre seu pai cego. Apenas no momento em que este pai, Tirésias, aparece, somos informados com clareza que Manto é a sua filha, que está viva, e a interlocutora é o fantasma da Rainha Jocasta, que está morta. Ficamos sabendo que Jocasta, assim como Édipo, não encontrou alívio na catástrofe da peça de Sófocles e que ela também é movida pelo desejo de encontrar este alívio com a revelação de quaisquer segredos putrefatos que ainda restem. "As desgraças do meu lar exigem que eu perceba os nós desta tragédia”, ela explica a Tirésias. "Só o conhecimento nos salva, meu amigo." Quando Tirésias se mostra relutante quanto a se aprofundar na investigação, Jocasta, com a visão dos mortos, para quem o passado e o futuro são igualmente acessíveis, inverte as posiçôes, revelando a Tirésias (e ao público) o segredo negro que jaz no coração da história do próprio Tirésias, um segredo que Rosa em parte tirou de mitos menos familiares e em parte recriou ele mesmo, para servir a seus próprios objetivos dramáticos e temáticos. Num primeiro momento, Tirésias resiste, alegando que ele "nada partilha” com Édipo, que não tem nenhum segredo negro parecido com o dele e, portanto, não precisa deste tipo de expiação radical como a que Édipo infligiu a si mesmo. Jocasta discorda. Há, é claro, mais sobre a história de Tirésias do que está revelado nas diversas versões do mito de Édipo, como sugere a presença física de Manto. Apenas ele, dentre todos os mortais, foi tanto homem quanto mulher e deu à luz sua filha Manto, enquanto estava na forma feminina. Rosa assinala a importância dessa dupla natureza numa versão anterior da peça, quando usou, como epígrafe, três versos de $A$ terra desolada de T. S. Eliott, em que Eliott apresenta Tirésias como um velho que palpita entre duas vidas com as tetas enrugadas de uma mulher. Esta parte do passado de Tirésias não foi imortalizada por um dramaturgo, mas por um poeta, Ovídio, que em suas Metamorfoses forneceu o locus classicus para esta famosa lenda em meras nove linhas.

Porque, de duas grandes copulantes, na verde floresta, os corpos das serpentes ele violentara com um golpe de cajado.

De homem, admiravelmente, feito mulher, sete outonos passara.

No oitavo, novamente às mesmas viu e disse:

"para que mude a sorte do autor no contrário, agora, do mesmo modo, que eu vos fira”. 
Atingidas as mesmas cobras, à forma primeira volta

e chega ao seu aspecto de nascença.

(1. 327-335)

Jocasta, no entanto, parece ter lido Ovídio (assim como leu Sófocles, a quem ela se refere explicitamente), e alega que o breve acerto de contas que ficou conhecido não dá conta de representar a história inteira ou verdadeira. "Afinal, a história das serpentes estava mesmo mal contada" reclama, sugerindo que se Tirésias, como Édipo, tivesse atraído a atenção direta de Sófocles e de seus semelhantes, seu destino seria muito diferente. Numa inteligente passagem metateatral, ela fala sobre a combinação de glória e sofrimento que lhe cabe como personagem central na "eternidade dos mitos", enquanto Tirésias, como um mero personagem secundário, está destinado a permanecer um ancião sábio e grave. "Nenhum poeta escreveu sobre ti o drama que mereces", ela observa, "e olha que há um belo enredo de paixão e desvario no teu passado."

Para corrigir essa falta, a própria Jocasta se torna esta voz poética até então oculta, dirigindo-se diretamente ao público e preenchendo as lacunas da história tradicional que, segundo ela, estão faltando. De acordo com essa versão, Tirésias se recusou a pagar tributo a Afrodite e a deusa rejeitada o castigou, vertendo em seu leito perfumes que deixaram Zeus louco de desejo. Tirésias, ameaçado com um estupro homossexual, apunhalou a "serpente erguida” do deus, que, por vingança, tirou a "serpente" de Tirésias, transformando-o numa mulher, forma na qual ele deu à luz Manto. Hera, sempre ciumenta (e com razão), quis matar as duas mulheres enviando um par de serpentes especiais, nitidamente fálicas, que matam depositando veneno na vagina. Tirésias protegeu Manto, mas recebeu a serpente em seu ór- gão. No entanto, ele apelou para a já pacificada Afrodite, que restaurou sua "serpente" e assim privou a serpente de Hera de encontrar um lugar em que pudesse depositar o seu veneno.

As serpentes copulantes de Ovídio foram então trocadas por um apinhado de imagens de serpentes, de conotação fálica muito mais óbvia e explícita que na história original, e a maldição não é o resultado direto do testemunho de uma união sexual normal, embora incomum, mas de um encontro homossexual específico. É claro que a atividade homossexual não era ignorada por Zeus. Entre os seus amantes, havia alguns homens e meninos, como o copeiro Ganimedes, mas o fato de Rosa ter trazido Tirésias para o círculo é uma criação nova, fundamentada na conexão intrínseca (já comum na Antiguidade) entre a imagem da serpente e o falo e também na imagem de Tirésias como figura central da androginia. Com esta história, algumas das imagens centrais desta versão ficam completamente expostas, mas, apesar do apelo e da intervenção de Jocasta, a peça de Rosa ainda não é a dramatização inédita dos feitos de Tirésias que ela demanda. Afinal, a peça não se chama "Um Tirésias”, mas “Um Édipo”, e esta sequência está na peça principalmente por ser útil para esclarecer a reorientação que Rosa vai operar na história de Édipo.

Depois da revelação da história secreta de Tirésias, Rosa retorna para Édipo e Jocasta. De forma surpreendente e nada convencional, Jocasta agora vê, do outro lado do túmulo, que todo amor é, de certo modo, incestuoso e que "não valia a pena ter-me enforcado por uma causa tão vulgar como esta." De todas as versões dramáticas anteriores, só conheço uma que adota essa posição menos condenatória para o pecado cometido por Édipo e Jocasta. Trata-se do Édipo do mais conhecido dramaturgo egípcio, Tawfiz al-Hakim, em que Édipo, numa longa cena antes do suicídio de Jocasta, discute com

1 Na versão do texto de Rosa para o inglês, foi usada a expressão "coupling snakes" (serpentes copulantes), como citada no título deste artigo. (N. da T.) 
ela - em termos de algum modo remanescentes das ideias de necessidade e liberdade em Schiller - que o amor dos dois, uma livre escolha, não é o pecado que parece ser pela perspectiva dos rigorosos ditames da ordem social e cultural. Enquanto essa era uma tensão central para alHakim, que a opera em boa parte do seu teatro, para Rosa, no entanto, a defesa do amor de Édipo e Jocasta fica a apenas um passo da sua questão central, a opção de deixar de lado aquele presumido motivo da maldição para procurar o motivo verdadeiro. "Foram outros os amores malditos" insiste Tirésias, "que fizeram a perdição da tua casa." Quando Jocasta dá a Tirésias "o fármaco das palavras", ela pede que ele faça o mesmo por ela, que lhe dê o remédio da revelação do que ela já esqueceu ou reprimiu, aquele segredo escondido que ainda lhe causa sofrimento.

Em seguida, há uma sequência que se emparelha com a revelação de Jocasta, mas que aqui não é recontada por Tirésias no papel de vidente, como Jocasta fez com a sua história, mas pelos espíritos, evocados por Tirésias, de duas das três principais figuras envolvidas. $\mathrm{O}$ espírito de Crísipo aparece primeiro, falando por si, enquanto Tirésias "sai discretamente". Depois, Tirésias volta, possuído pelo pai de Crísipo, Pélops, e falando em seu nome. Essa parte da peça sugere outra forma importante de "mitodrama fantasmático", a do Nô, teatro clássico do Japão, no qual um espírito inquieto retorna diversas vezes à terra para se libertar das memórias violentas do seu passado, recontando-as ou ainda reencenando-as. A história que Crísipo conta, e o próprio personagem Crísipo, não são familiares para a maior parte dos espectadores de teatro, mas ele está no centro da reconfiguração estrutural e temática que Rosa faz da história de Édipo. Como Eurípedes, Rosa pega uma parte ou variação menos familiar de um mito conhecido e a desloca para o centro do palco para contar uma história muito diferente.

A narrativa essencial que Crísipo conta segue a história normalmente aceita, senão mais conhecida, do seu infortúnio. O Rei Laio, hóspede no Palácio do Rei Pélops, tem uma paixão ilícita pela encantadora beleza do filho de seu anfitrião, rapta-o e força uma relação. Em algumas versões da história, Crísipo se mata de vergonha. Rosa faz a sua morte parecer particularmente adequada, ao fazer o desesperado Crísipo fugir do seu sequestrador e, na escuridão, cair morto no desfiladeiro do Rio Cérbero, que "serpenteava como uma víbora negra". A forma da história, é claro, se emparelha bastante com aquela que acabamos de ouvir a respeito de Tirésias - a paixão homossexual cega, a resistência a e a fuga (rematada com a imagem da serpente) e o consequente desastre (a morte de um lado, a maldição divina de outro).

Agora o espírito do horrorizado pai de Crísipo, Pélops, toma posse do corpo de Tirésias e, com o corpo do filho no colo, pronuncia a fatal maldição da casa de Laio: que o Rei culpado fique estéril e, se isto algum dia não for cumprido, que "o filho que te nasça seja o assassino de seu pai", e que este filho "seja a desgraça da mãe que o gerou, regressando ao leito dela para cumprir o teu papel inacabado de macho." Assim, o crime de tentativa de estupro homossexual resultante em morte é deslocado, pela maldição de Pélops, para os crimes de parricídio e incesto, como punição - mas não para Édipo, por matar o pai e deitar-se com a mãe, e sim para Laio, que sofrerá a morte e a desonra da sua própria relação sexual como pagamento por seu crime. Agora, até Jocasta deve admitir que foi "este o início da nossa ruína”, mas cada um dos participantes na tragédia também deu a ela sua contribuição. A primeira contribuição de Jocasta foi readmitir Laio na cidade quando ele retorna desgraçado como um mendigo errante, rejeitado por deuses e homens. Quando os portôes da cidade são trancados diante dele, ela apela para a ajuda sobrenatural e, ao fazê-lo, alista-se aos cúmplices da paixão anormal de Laio. Ela não apela para Afrodite, cujos poderes se estendem tanto a inclinaçôes homossexuais quanto heterossexuais, mas a Orfeu, que ela chama de "bardo pederasta", que renunciou a todas as mulheres após a perda de Eurídice e "desenca- 
minhava maridos e filhos com o som da sua lira”. A sua presunção de que Orfeu iria compreender e se compadecer da "loucura de Laio" estava correta e, em resposta ao seu apelo, um canto misterioso abre os portões da cidade. Laio retorna, então, para sua mulher e sua cidade, a primeira maldição, a esterilidade, é vencida após muitos sacrifícios e o condenado Édipo é concebido.

"O resto da história já tu sabes", diz Jocasta, quando retorna para resumir a conhecida história do abandono de Édipo, de sua juventude em Corinto, e o assassinato do seu pai. Como nas adaptações mais comuns, Jocasta aponta que "Laio estava acompanhado de alguém quando o filho lhe tirou a vida em duelo, mas ninguém sabe o paradeiro da testemunha." Essa desaparecida testemunha da morte de Laio é obviamente uma figura central em quase todas as versões da história, mas, tradicionalmente, trata-se de um dos criados de Laio, que escapou da ira de Édipo e voltou para viver calmamente na cidade, com medo de contar o que sabe, até o momento em que é convocado e obrigado a falar.

Aqui, mais uma vez, Rosa deixa a tradição para trás de maneira significativa. Sua testemunha surpresa não é um criado desconhecido, mas - o que é típico nessa peça - um fantasma e, além disso, um fantasma a que já fomos apresentados. Nossa expectativa de ouvir o depoimento-clímax dessa "testemunha surpresa” é, no entanto, mantido em suspenso por uma cena que intervém no crescendo da tensão, uma cena que reforça questôes temáticas centrais para a peça, além de remeter à abertura e apontar para a conclusão da peça. Manto aparece para introduzir um cego desconhecido, que Jocasta imediatamente presume ser Édipo, mas, antes que ele apareça, há ainda um adiamento, no qual Jocasta, Tirésias e Manto discutem os planos da jovem para o futuro. Apesar do treinamento e da inspiração que o pai lhe deu, ela acha que não tem talento nem inclinação para ser xamã. "Competir com as loucas sagradas de Delfos não está nos meus planos", ela afirma.
(Este tema não é desenvolvido, mas parece que Rosa está fazendo uma piada interna para o raro espectador que talvez saiba que, pelo menos de acordo com algumas versões do mito, Manto permanece na cidade de Tebas até sua queda para os Epígonos, filhos dos Sete, e depois desse fato ela é mandada para Delfos para se tornar a sacerdotisa sagrada do local). Seu sonho, como foi apontado na abertura da peça, é ser ator, "decorar os papeis de Dioniso."

Em Manto, os elementos metateatrais da peça de Rosa estão casados com o tema fundamental da ambiguidade sexual. Ela se ressente da tentativa humana de separar a celebração daquele que, de todos os deuses, é o mais sexualmente ambíguo, Dioniso, em práticas masculinas e femininas distintas: as emotivas, até mesmo histéricas, entregues aos cuidados das mulheres, e as intelectuais, aos cuidados dos homens. Manto, que prefere o aspecto "masculino" do deus, é então excluída, por causa do seu gênero, da relação com este aspecto do deus, como ela explica a Jocasta na conversa inicial:

Os homens foram expulsos dos ritos das bacantes, e agora proíbem as mulheres de entrar no jogo das máscaras. Eu desprezo as procissões de histéricas. Adoro é a inteligência de Dioniso que os homens guardam no palco só para eles.

Seu pai, no entanto, aponta que isso é impossível, que logo descobririam, de uma maneira ou de outra, que ela não tem a serpente, $o$ "membro viril". Para isso, Manto (ainda) não tem resposta e traz Édipo, que estava à espera. Ainda não é a testemunha misteriosa que faltava, mas o próprio Édipo, cego. Como a morta Jocasta, cuja presença ele sente, mas a quem ele não reconhece, Édipo confessa a Tirésias que seu sacrifício não aplacou seu sofrimento, que sua alma ainda está doente. Pressionado por Tirésias, ele reconta a visão que o atormenta. Ele descreve em detalhes vívidos a morte de Laio, seguindo a história tradicional do confronto na estrada, em que nenhum dos homens 
estava disposto a ceder. "É esta a lei dos machos solitários que se enfrentam numa estrada deserta", ele conclui. "Apenas um deles poderá seguir caminho."

A esta altura, entretanto, a testemunha que faltava finalmente aparece. É o fantasma de Crísipo, que acusa de mentirosa a história de Édipo e promete revelar a verdade. Como na peça de Sófocles, agora chegamos ao ponto em que estamos à beira da revelação final e decisiva, quando, na peça de Sófocles, Édipo insiste na exposição da verdade enquanto todos ao seu redor, desde Jocasta até o desafortunado criado que carrega o conhecimento dos fatos, tentam em vão impedir a revelação. $\mathrm{Na}$ releitura de Rosa, Jocasta tenta novamente silenciar a história fatal, mas desta vez é o mensageiro quem encaminha a ação, impondo a verdade a um Édipo relutante que, assim como Jocasta e Tirésias, omitiu alguns fatos essenciais e construiu uma história diferente, na qual ele mesmo acabou por acreditar. Tirésias alega ser velho e fraco demais para servir de médium para o espírito jovem de Crísipo, mas, enquanto ele protesta, Manto aceita o papel. Então, pela terceira vez na peça, temos o padrão do fantasma (ou xamã) psicanalista obrigando um personagem a confrontar uma memória reprimida. Cada uma das repressóes prévias estava ligada à homossexualidade masculina, assim como esta, a terceira e mais crítica de todas.

Agora é a vez de Crísipo servir de contador de histórias de acontecimentos passados, e ele conta como, enquanto vagava no reino dos espíritos, pensando em Laio, algum deus o transportou para a estrada fatal, onde encontrou Laio, que viu nele a imagem combinada do amante morto e do filho. Esse relato invoca o espírito de Laio, que toma o corpo de Tirésias e fala por seus lábios. Eles recriam o encontro na estrada e se abraçam, uma imagem que finalmente destrava a memória reprimida do próprio Édipo. Agora ele se lembra do que viu e o que disparou a sua raiva assassina - não foi o desafio de outro homem num caminho estreito demais para dois homens passarem, mas algo mais cho- cante e proibido: "dois homens enroscados como serpentes ${ }^{2}$ na encruzilhada. Um mais velho e outro mais novo, com idade para ser seu filho." Assim, Rosa desloca engenhosamente a imagem tradicional que mudou o sexo de Tirésias para o momento principal do embate, no ponto em que três estradas se encontram, amarrando-a de volta ao pecado original de Laio e trazendo à superfície, com clareza, suas sugestôes homossexuais masculinas. (Hoje, no sul da Índia, de acordo com algumas crenças populares, o homossexualismo, "a enfermidade feminina”, pode ser causada pela visão que mudou o sexo do vidente, a das serpentes copulantes).

Agora, enquanto os espíritos de Crísipo e Laio destravam a memória de Édipo ao re-encenarem o abraço fatal, o espírito de Laio e o cego Édipo re-encenam o diálogo que levou Édipo a desferir o golpe. Laio observa que se todos os filhos querem matar o pai e tomar o seu lugar, então todos os pais querem matar os filhos para prevenir a substituição. Édipo, cego pela perversão de Laio, não consegue ou não quer ouvir seu argumento e o mata. $\mathrm{O}$ espírito de Laio desaparece, mas cada um dos sofredores tem a sua lição, de acordo com cada um dos personagens, a partir dessas revelações. Para Crísipo, que tem a visão dos mortos, a lição é a cegueira de Édipo, e da maior parte da humanidade, para o fato de que nem a vida nem os deuses são unívocos, mas multifacetados e ambíguos. Para Jocasta, o outro espírito, pais e filhos vão continuar envolvidos, como sempre estiveram, em rivalidade mortal. Para Édipo, trata-se da resolução da maldição de Pélops sobre todos eles, mas ele apela para a palavra final de Tirésias, que agora está morrendo.

A palavra final de Tirésias, no entanto, não é para Édipo, mas para sua filha Manto - e a princípio parece estar muito distante da revelação que Édipo esperava. Na verdade, porém, à maneira do vidente/xamã, essa resposta de fato apresenta uma resposta ao apelo de Édipo, mas de maneira oblíqua, que não mostra sua relevância de imediato. Ele dá a ela uma ordem: que vá para Lesbos, uma ilha na qual ela poderá reali- 
zar seu sonho, já que as mulheres não podem subir ao palco. Aparentemente, trata-se de um simples final feliz e inesperado para a personagem que serve como uma espécie de moldura para esta releitura não-convencional, mas é muito mais que isso. O que não é mencionado, embora isso esteja claro para quase qualquer espectador, é a forte associação cultural de Lesbos com o homossexualismo feminino. A líder intelectual e artística da ilha, que também não é mencionada, é a poetisa Safo, uma das mulheres mais cultas da Grécia Clássica. Não seria, portanto, nada surpreendente se nesta ilha as mulheres fizessem peças ou prestassem culto a Dioniso, como Manto gostaria de fazer, com a mente.

É óbvio que esta conclusão está em sintonia com a maior parte dos temas que predominaram na peça, especialmente o teatro, o homossexualismo e a perturbação ou desestabilização das expectativas quanto aos gêneros tradicionais de cada papel. O aparecimento do homossexualismo feminino, nem discutido nem implícito em toda a imagética homossexual da peça, levanta uma série de questóes interessan- tes. Será que Lesbos representa uma espécie de fuga utópica das serpentes copulantes que assombraram o resto dessa história sombria, com suas herdadas maldições e com a rivalidade mútua e continuamente destrutiva entre pais e filhos? Ou será que Lesbos apenas inverte os conceitos binários estabelecidos, agora que as mulheres se apoderaram de atividades masculinas, como o teatro? Ou ela serve como mais um novo exemplo da percepção, do espírito de Crísipo, de que as pessoas devem reconhecer que a vida é múltipla em suas formas e manifestaçóes e que a verdadeira harmonia com o universo vem da sabedoria em reconhecer e aceitar essa diversidade? Como qualquer drama bem pensado, este permanece com o final em aberto, deixando que cada leitor, espectador ou produtor encontre nele as suas próprias verdades. Os temas desta peça rica e interessante são complexos e entrelaçados, como as serpentes copulantes, e presenciar essa peça, assim como presenciar o encontro das serpentes, sem dúvida abala e transforma o espectador. Afinal, isto é o que se espera do teatro na sua melhor forma.

RESUMO: O ensaio analisa a releitura que o dramaturgo português Armando Nascimento Rosa faz de Édipo Rei, fornecendo pistas para a avaliação do tratamento dramático múltiplo a que submete a tragédia de Sófocles, relacionando as múltiplas versões trabalhadas ao conceito de suplemento em Derrida. Discorre sobre o fato de Rosa não apenas ampliar a história de Édipo, mas darlhe um foco novo, não só quanto aos personagens, mas também no que diz respeito ao tema. Enquanto o centro emocional da lenda é a transgressão do incesto, na versão do dramaturgo a transgressão anterior de Laio, e não a de Édipo, é o pecado inicial, deslocando a atenção de um amor culturalmente proibido, o incesto, para outro, o homossexualismo, cujo imaginário permeia a peça e guia tanto a trama quanto as revelaçóes.

PALAVRAS-CHAVE: dramaturgia contemporânea; mitodrama; Armando Nascimento Rosa; Um Édipo; Sófocles. 